\title{
Salmonella Enteritidis in Broiler Chickens: Isolation, Antibiotic Resistance Phenotyping and Efficacy of Colistin on Control of Experimental Infection
}

\author{
Mohamed M. Amer ${ }^{1 *}$, Aziza M. Amer ${ }^{2}$, Eman R. Hassan $^{3}$ and Aly M. Ghetas ${ }^{3}$ \\ ${ }^{1}$ Department of Poultry Diseases, Faculty of Veterinary Medicine, Cairo University, P.O. Code 12211 Giza, Egypt \\ ${ }^{2}$ Department of Pharmacology, Faculty Veterinary Medicine, Cairo University, Giza, Egypt. P.O. Code 12211, Giza, \\ Egypt; ${ }^{3}$ Department of Poultry Diseases, Veterinary. Research Division, National Research Centre, P.O. Code 12311 \\ Dokki, Giza, Egypt \\ *Corresponding author: profdramer@yahoo.com
}

\begin{abstract}
Article History: $\quad$ Received: November 22, 2019 Revised: December 18, $2019 \quad$ Accepted: January 06, 2020
ABSTRACT

Out of 400 examined samples 45 suspected Salmonella isolates (11.25\%) were obtained $19(9.5 \%)$ out of apparently healthy and $26(13 \%)$ from diseased chickens. Intestinal samples had more isolates $(29,14.5 \%)$ more than liver $(16$, $8 \%)$. Identified S.Enteritidis from suspected salmonella was $16 / 45(35.6 \%)$ with a rate of $8 \%$ out of the examined 400 samples, $6(3.0 \%)$ out of apparently healthy and $10(5.0 \%)$ from diseased chickens. Intestinal samples had more isolates $(11,5.5 \%)$ than liver $(5,2.5 \%)$. The Antibiotics susceptibility profile of $S$. Enteritidis isolates revealed $100 \%$ resistance to trimethoprim/sulfamethoxazole, followed by oxacillin (62.5\%), 56.3\% for each of ampicillin, clindamycin, enrofloxacin and doxycycline, $50 \%$ for chloramphenicol, $43.8 \%$ for streptomycin, 37.5\% to cephalosporins and $18.8 \%$ for colistin. Tested S. Enteritidis isolates are classified into 11 profiles and are resistant to two - nine antibiotic classes with resistant index 0.2- 0.9. Only two isolates are NDR (12.5\%), most of isolates 10/16 (62.5\%) are MDR and 25\% are EDR to 8-9 antibiotics. Clinical signs in experimentally infected chickens appeared at $2^{\text {nd }} \mathrm{dpi}$, mortality started at the $4^{\text {th }}$ to reach $27.5 \%$ in infected nontreated and $5 \%$ in colistin treated. Signs and lesions were markedly severe in infected nontreated than treated. S. Enteritidis was re-isolated from dead infected birds. S. Enteritidis intestinal count in sacrificed infected nontreated was higher than treated. Colistin treated group showed higher FCR, EEF and CV\% (1.52, 402.8 and 6.12\%) than infected non-treated (1.73, 222.6 and 14.83\%). It could be concluded that $S$. Enteritidis is prevalent in broiler chicken flocks. Most of the isolates are MDR. Experimental infection of broiler with S. Enteritidis field isolates resulted in high mortality and the addition of colistin sulphate in drinking water controlled the infection and restores the productivity of infected broiler chickens.
\end{abstract}

Key words: Broiler, S. Enteritidis, isolation, Multidrug resistance, Experimental infection, Colistin.

\section{INTRODUCTION}

Bacterial poultry diseases cause severe economic losses in poultry industry, one of these diseases is Salmonella Enteritidis (S.Enteritidis), which is induced Salmonellosis in poultry and food poisoning in human (Akinyemi et al., 2007). S. Enteritidis is one out of approximately 10-20 serovars of group 2 of genus Salmonella of the family Enterobacteriaceae. This group consists of non-host adapted and invasive serovars that are able to cause an invasive infection in poultry and may be capable of infecting humans (Hafez, 2001).

$S$. Enteritidis in poultry causes serious economic losses due to increase mortality rate (4-50\%) and decrease in egg production worldwide (Shittu et al., 2014). In broiler chickens $S$. Enteritidis causes variable mortality 20-96\% (Barrow, 1991) especially in vertical transmitted chicks, characteristic pericarditis with necrotic foci and petechial hemorrhage on liver (O'Brien, 1988). During the last few years over $85 \%$ of broiler chickens infections was caused by $S$. Enteritidis from products of poultry origin (Altekruse et al., 2006). Organism may cause systemic infection in chicks and laying hens accompanied by prolonged fecal shedding. Some variations in the mortality rates, clinical symptoms, fecal shedding and frequency of production of contaminated eggs were observed in the chicks and hens experimentally infected with S. Enteritidis isolates (Suzuki, 1994).

Cite This Article as: Amer MM, AM Amer, ER Hassan and AM Ghetas, 2020. Salmonella Enteritidis in broiler chickens: isolation, antibiotic resistance phenotyping and efficacy of colistin on control of experimental infection. Int $\mathrm{J}$ Vet Sci, 9(2): 267-272. www.ijvets.com (@2020 IJVS. All rights reserved) 
Persistent environmental contamination of poultry houses is an important factor in the maintenance of $S$. Enteritidis and other salmonellas in poultry flocks (Baggesen et al., 1992). Moreover, it was found that Salmonellas persist in dry livestock buildings for many months (Bale et al., 1993). Soliman et al. (2018) reported that incidence rate of salmonella $(20.24 \%)$ was highly reported on $5^{\text {th }}$ week age out of them $56 \%$ was $S$. Enteritidis, and salmonella infection still prevalent in poultry farms in Egypt.

Reducing $S$. Enteritidis in chicken intestinal tract could reduce contamination of poultry products (Altekruse et al., 1993), therefore, antibiotic treatment reduced the prevalence of infection S. Enteritidis but did not eliminate the organism (Seuna et al., 1980), while antibiotic followed competitive exclusion shown to be effective in eliminating Salmonella from chickens (Reynolds et al., 1997).

The goal of antimicrobial susceptibility testing of bacterial isolates is to detect possible drug resistance and to assure there susceptibility to drugs of choice for particular infections (Jorgensen and Ferraro, 2009). The isolates had multiple antibiotic resistance (MAR) index $\geq$ 0.3 indicated that these isolates were multidrug resistant (resistant to 3 or 4 class of antibiotics), expanded drug resistant (resistant to $\geq 5$ antibiotics classes). The most resistance patterns observed among the MDR isolates suggesting that this resistant isolate originated from a high-risk source of contamination where antibiotics are often used or that a large proportion of the bacterial isolates have been pre-exposed to several antibiotics (Christopher et al., 2013).

Colistin sulphate is one of used antibiotics to control $S$. Enteritidis infection in broilers. It was reported that colistin decreases the rate of infection and contamination of carcasses together with improving live weight gain by $14 \%$ and the feed conversion rate by $8 \%$ (Fard, 2004). Unfortunately this antibiotic showed multi-drug resistance nowadays together with antimicrobial genetic elements that can be exchanged between intestinal bacteria (da Costa et al., 2013).

The objective of the present study was to isolate S.Enteritidis from apparent healthy and diseased broiler chickens at marketing age (35-42 days), detection of their antibiotic resistance phenotype, and study the ability of colistin sulphate in control of $S$. Enteritidis in experimentally infected broiler chickens.

\section{MATERIALS AND METHODS}

\section{Samples}

A total of 400 aseptically collected samples (1 gram from livers and $1 \mathrm{gm}$ intestinal content close to the diverticulum) representing 100 apparent healthy and 100 diseased broiler chickens showing diarrhoea and respiratory distress at 35 to 42 day old age. Collected samples were transported to our laboratory under cooling for bacterial isolation.

\section{Isolation of Salmonella}

Both liver homogenate and intestinal content $(1 \mathrm{ml})$ was aseptically added to $10 \mathrm{ml}$ of Rappaport-Vassiliadis (RV) broth and incubated at $42^{\circ} \mathrm{C}$ for $24 \mathrm{hs}$. The broths were subcultured on xylose-lysine-desoxycholate (XLD) agar (Oxoid Limited, UK) and aerobic incubated at $35^{\circ} \mathrm{C}$ for $24 \mathrm{~h}$. Red to pink colonies with black center were picked and kept in $25 \%$ glycerol broth at $-80^{\circ} \mathrm{C}$ for further identification.

\section{Identification of Isolates}

The obtained isolates were identified and characterized on the basis their colonial morphological, Gram's stained for morphological and stain character and biochemical properties (Forbes et al., 2002; Greenwood et al., 2005). Biochemical characterization was done on the basis API identification kits (API System, France) were analyzed using Bergey's manual of systematic bacteriology (Sneath et al., 1986).

\section{Serological identification}

The serogroup characterization of isolates was performed via slide-agglutination test according to Quinn et al. (2002). Diagnostic poly and monovalent Salmonella $\mathrm{O}$ and $\mathrm{H}$ antisera were used for serological identification of the obtained $S$. Enteritidis isolates (Salmonella diagnostic antisera, PRO-LAB, 3 Bassendale Road, Bromborough, Wirral, Merseyside, CH62 3QL, UK. Vision antisera are prepared for use in serological identification of organisms belonging to the genus Salmonella according to Kauffmann White classification (Kauffmann, 2001).

\section{In vitro Antimicrobial susceptibility test}

The antibiotics susceptibility phenotype or profile of the identified of $S$. Enteritidis isolates were determined using disc agar diffusion (DAD) technique (CLSI, 2016). Separate and similar colonies on solid media plate were emulsified in $2 \mathrm{ml}$ of normal saline and the turbidity was adjusted to McFarland standard tube 0.5. All isolates were tested for resistance to 10 antimicrobials including: ampicillin $10 \mu \mathrm{g}$ (AMP), calindamycin $2 \mu \mathrm{g}$ (DA) cephalosporins $30 \mu \mathrm{g}$ (CVN 30), colistin $10 \mu \mathrm{g}$ (CT), chloramphenicol $30 \mu \mathrm{g}$ (C30), doxycycline $5 \mu \mathrm{g}$ (DO), enrofloxacin $5 \mu \mathrm{g}$ (ENR), oxacillin $30 \mu \mathrm{g}$ (OX), streptomycin $10 \mu \mathrm{g}(\mathrm{S})$, trimethoprim/sulfamethoxazole

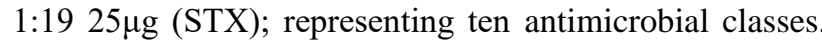
Antibiotic sensitivity disc were obtained from Oxoid Limited, UK. Sensitivity and resistance were determined according to CLSI (2016). E. coli laboratory isolate susceptible to all of the antibiotics, was used for control.

\section{Determination of multiple antibiotic resistances index}

Isolate MAR index was determined by using the formula $\mathrm{MAR}=$ The number of antibiotics to which the test isolate depicted resistance/Total number of antibiotics to which the test isolate has been evaluated for susceptibility (Paul et al., 1997). For interpretation of antimicrobial susceptibility, narrow drug resistance (NDR) isolates have index $<0.3$, isolates have index $\geq 0.3$ 0.7 are multidrug resistant (resistant to 3 or 7 class of antibiotics) are MAR or extensively drug-resistant (XDR) bacterial isolates resistant to 8 or 9 antibiotics classes and pan drug resistant (PDR) isolates non susceptible to all agents in all antimicrobial categories (Christopher et al., 2013). 


\section{Chickens}

A total 130, 1-day-old Cobb broiler chicks as hatched; ten chicks were sacrificed and examined bacteriologically to prove their freedom from $S$. Enteritidis infection. The birds were kept in cleaned and disinfected separate cages and given feed and water ad libitum till the age of 21 days. All birds were vaccinated using live Hitchner $\mathrm{B}_{1}+\mathrm{IB}$ and La Sota vaccine strains via eye drop at 5 and 16 days of age, respectively. Infectious bursal disease live $228 \mathrm{E}$ was given in drinking water at 14 days.

\section{Ration}

Commercial starter and grower broiler chicken ration were given till 21 and 32 days of age, respectively. The used commercial balanced ration based on yellow corn and soya bean according breed requirements.

\section{Colistin sulphate}

Colistin6M ${ }^{\circledR}$ : each gm contains 6000.000 IU Colistin sulphate. Lot No. 150415. Colistin6 $\mathrm{M}^{\circledR}$ is produced by Jordan Vet and Agr Med. Ind. Co - Amman - Jordan. It was used in drinking water in dose of $0.5 \mathrm{gm} / \mathrm{lit}$ for 5 successive days.

\section{Experimental infection}

The inoculum was prepared according to the method of Timms et al. (1990). At 21 days of age, each bird in the experimentally infected groups was inoculated orally with $0.5 \mathrm{ml} /$ containing $10^{9} \mathrm{CFU} / \mathrm{ml} \mathrm{S}$. Enteritidis (Okamoto et al., 2007).

\section{Re-isolation of $S$. Enteritidis}

a. Dead birds post challenge was collected and the liver, heart, spleen and caecum were used for $S$. Enteritidis re-isolation. Samples were inoculated into RV broth, incubated at $37^{\circ} \mathrm{C}$ for $24 \mathrm{hr}$, streaked onto XLD agar and incubated at $37^{\circ} \mathrm{C}$ for $24 \mathrm{hr}$. Suspected colonies were identified morphologically and biochemically.

b. At 3,5 and 7 days after treatment 2 birds were sacrificed. Equal amount (about $1 \mathrm{gm}$ ) from duodenum, middle part close to the diverticulum and caecum were collected and mixed. One gram from each sample was subjected to total colony count on XLD agar plate containing streptomycin $10 \mathrm{mg} / \mathrm{ml}$.

\section{Experimental design}

A total number of 120, 21-day chicks divided into 3 equal groups, 40 chicks in each. Chicks of groups 1 and 2 were infected by gavage into the crop, each by $1.5 \mathrm{ml}$ containing $10^{9} \mathrm{CFU} / \mathrm{ml} \mathrm{S}$. Enteritidis. Group 3 was kept as negative non-infected non-treated. All chicken groups were daily observed for clinical signs, mortalities and gross lesions in dead birds. Colistin sulphate $(0.5 \mathrm{gm} / \mathrm{lit})$ was given to group 1 start from $3^{\text {nd }}$ day post infection (dpi); with the appearance of clinical signs and mortality; for 5 successive days. Samples from dead birds including liver, heart, spleen and cecum were aseptically collected from each group post infection for $S$. Enteritidis re-isolation. Intestinal content at 3,5 and 7 day from medication were aseptically collected for recording total $S$. Enteritidis count. Total feed intake (TFI), and average body weight gain (BWG) were recorded for calculation of FCR with calculation of European efficacy factor (EEF) and production $\mathrm{CV} \%$ at the $5^{\text {th }}$ week of age.

\section{Production parameters}

FCR, livability, EEF and CV\% were calculated for the same group birds during a given period (including weight gain of birds which died during the given period) according to Sainsbury (1984).

\section{RESULTS AND DISCUSSION}

In the present study, out of 400 examined samples 45 suspected isolates $(11.25 \%)$ were obtained $19(9.5 \%)$ out of apparent healthy and 26 (13\%) from diseased chicken (Table 1). similar isolation rate of salmonella from chicken was 14\% (Rabie et al., 2012). Intestinal samples had more isolates $(29,14.5 \%)$ more than liver $(16,8 \%)$ (Table 2). The highest incidence of Salmonella isolation was from the intestine than liver agree with those previously reported by Menghistu et al. (2011). Also, Gong et al. (2014) reported that prevalence of Salmonella sp. in rectal swab samples were $9.8 \%$ in chicken examined farms. Fasure et al. (2012) reported isolation of salmonella (12.5\%) from human and broilers. Salmonella strains were isolated $38 \%$ of the screened 5week-old broiler flocks (El-Sharkawy et al., 2017). Similar to our incidence of salmonella from liver was $12 \%$ (Mohamed (1998), while, Putturu et al. (2012) reported higher $(50 \%)$ rate of salmonella isolation from liver.

Regarding the identified $S$. Enteritidis out of the examined samples (Table 1) 16 isolates $(8.0 \%)$ were obtained $6(3.0 \%)$ out of apparent healthy and $10(5.0 \%)$ from diseased (Table 1). Rate of identified S. Enteritidis from salmonella isolates were 16/45 (35.6\%). Our results are close to those reported by Fasure et al. (2012) $6.25 \%$ and lower than previously reported the incidence of $S$. Enteritidis out the examined samples as $40 \%$ (Abdallah, 1995), 81.5\% (Carli et al., (2001), 52.9\% (Marin et al., 2011), 37.25\% (Abd El-Ghany et al., 2012a), and 58.33\% (Rabie et al., 2012). Apparent healthy and diseased intestinal samples had $S$. Enteritidis isolates (11, 5.5\%) more than liver $(5,2.5 \%)$ (Table 2). Similar results were obtained by El-Sharkawy et al. (2017) who reported that $S$. Enteritidis was $2(0.98 \%)$ from liver and $1(0.49 \%)$ from intestine.

Antibiotics susceptibility profile (Table 3) of $S$. Enteritidis isolates revealed $100 \%$ resistance to Trimethoprim/Sulfamethoxazole, followed by Oxacillin (62.5\%), 56.3\% for each of ampicillin, Clindamycin, Enrofloxacin and Doxycycline, 50\% for Chloramphenicol, $43.8 \%$ for Streptomycin, $37.5 \%$ to Cephalosporins and lowest percentagefor Colistin(18.8\%). Previous worker reported similar resistant results, $31.25 \%$ to ciprofloxacin and $87.5 \%$ to amoxicillin (Aditya, 2015); $100 \%$ to ampicillin and $90.6 \%$ to tetracycline (Fasure et al., 2012); $82.2 \%$ to ampicillin, $80 \%$ to tetracycline and $54.2 \%$ to chloramphenicol (Asif et al., 2017). Also, 65.6\% of clinical isolates were resistant to ampicillin and tetracycline (Mezal et al., 2014). In contrast El-Sharkawy et al (2017) reported that S. enterica serovar Enteritidis isolates were susceptible to all tested antimicrobials. 
Int J Vet Sci, 2020, 9(2): 267-272

Table 1: Isolation (suspected) and identification of S. Enteritidis from intestine and livers of healthy and diseased broiler chickens $(\mathrm{n}=100)$

\begin{tabular}{ccccc}
\hline Chickens & Organs & $\begin{array}{c}\text { No. of Suspected } \\
\text { isolates }\end{array}$ & $\begin{array}{c}\text { No. of Identified } \\
\text { isolates }\end{array}$ & $\%$ of S. Enteritidis \\
\hline Apparent & Intestine & $12(12 \%)$ & $4(4 \%)$ & 33.3 \\
healthy & Liver & $7(7 \%)$ & $2(2 \%)$ & 28.6 \\
Diseased & Intestine & $17(17 \%)$ & $7(7 \%)$ & 41.2 \\
& Liver & $9(9 \%)$ & $3(3 \%)$ & 33.3 \\
Total & 400 & $45(11.25 \%)$ & $16(8.0 \%)$ & 35.6 \\
\hline
\end{tabular}

Table 2: Isolation (suspected) and identification of S. Enteritidis from Intestine and livers of broiler chickens $(\mathrm{n}=200)$.

\begin{tabular}{lcc}
\hline Organs & No. and \% Suspected & No. and \% of Identified \\
& isolates & isolates \\
\hline Intestine & $29(14.5 \%)$ & $11(5.5 \%)$ \\
Liver & $16(8 \%)$ & $5(2.5 \%)$ \\
\hline
\end{tabular}

Table 3: Antibiotics profile of $S$. Enteritidis isolated from broiler chickens.

\begin{tabular}{|c|c|c|c|c|c|c|c|c|c|c|c|}
\hline & ions & AMP & DA & CVN & CT & $\mathrm{C}$ & DO & ENR & OX & $\mathrm{S}$ & STX \\
\hline $\mathrm{R}$ & $\begin{array}{c}\text { No } \\
\%\end{array}$ & $\begin{array}{c}9 \\
56.3 \%\end{array}$ & $\begin{array}{c}9 \\
56.3 \%\end{array}$ & $\begin{array}{c}6 \\
37.5 \%\end{array}$ & $\begin{array}{c}3 \\
18.8 \%\end{array}$ & $\begin{array}{c}8 \\
50 \%\end{array}$ & $\begin{array}{c}9 \\
56.3 \%\end{array}$ & $\begin{array}{c}9 \\
56.3 \%\end{array}$ & $\begin{array}{c}10 \\
62.5 \%\end{array}$ & $\begin{array}{c}7 \\
43.8 \%\end{array}$ & $\begin{array}{c}16 \\
100 \%\end{array}$ \\
\hline
\end{tabular}

R: Resistant. AMP: Ampicillin. DA: Calindamycin. CVN: Cephalosporins. CT: Colistin. C: Chloramphenicol. DO: Doxycycline. ENR: Enrofloxacin. OX: Oxacillin. S: Streptomycin .STX: Trimethoprim/Sulfamethoxazole.

Table 4: Distribution of antibiotic resistance rates, index and class of S.Enteritidis isolates.

\begin{tabular}{|c|c|c|c|c|c|c|}
\hline \multirow{2}{*}{$\begin{array}{l}\text { Antibiotic } \\
\text { pattern profile }\end{array}$} & \multirow[t]{2}{*}{ Antibiotic } & \multirow{2}{*}{$\begin{array}{l}\text { No of } \\
\text { isolates }\end{array}$} & \multicolumn{4}{|c|}{ Resistant } \\
\hline & & & No of Antibiotic & Index & Percent & Class \\
\hline 1 & DA, STX & 2 & 2 & 0.2 & $12.5 \%$ & NDR \\
\hline 2 & AMP, OX, STX & 1 & 3 & $0.3-0.7$ & $62.5 \%$ & MDR \\
\hline 3 & DA, CVN, DO, STX & 2 & 4 & & & \\
\hline 4 & $\mathrm{C}, \mathrm{DO}, \mathrm{ENR}, \mathrm{OX}$ & 1 & & & & \\
\hline 5 & AMP, CVN, C, ENR, STX & 2 & 5 & & & \\
\hline 6 & AMP, DA, DO, OX, S, STX & 2 & 6 & & & \\
\hline 7 & AMP, DA, CVN, ENR, OX, STX & 1 & & & & \\
\hline 8 & DA, C, DO, ENR, OX, S, STX & 1 & 7 & & & \\
\hline 9 & AMP, CT, C, DO, ENR, OX, S, STX & 3 & 8 & $0.8-0.9$ & $25 \%$ & XDR \\
\hline 10 & AMP, DA, C, DO, ENR, OX, S, STX & 1 & 9 & & & \\
\hline
\end{tabular}

AMP: Ampicillin. DA: Calindamycin. CVN: Cephalosporins. CT: Colistin: C: Chloramphenicol. DO: Doxycycline. ENR: Enrofloxacin. OX: Oxacillin. S: Streptomycin. STX: Trimethoprim/Sulfamethoxazole. NDR: Narrow drug-resistant, index < 0.3 . MDR: Multidrug-resistant, index, 0.3-0.7. XDR: Extensively drug-resistant, index 0.8- 0.9.

Table 5: Mortality rate in S. Enteritidis infected treated and control chicken group $(\mathrm{n}=40)$.

\begin{tabular}{ccccc}
\hline Group & Infection & Treatment & No of dead birds after infection & Mortality rate \\
\hline 1 & + & Colistin & 2 & $5 \%$ \\
2 & - & - ve & 0 & 0 \\
3 & + & Non-treated & 11 & $27.5 \%$ \\
\hline
\end{tabular}

Table 6: Performance of treated and control $S$. Enteritidis infected broiler chicken groups at the $5^{\text {th }}$ week of age.

\begin{tabular}{ccccccccc}
\hline Gr & Infection & Treatment & ABW/gm & AFI/gm & FCR & Livability \% & EEF* & CV\%** \\
N0. & & & Mean \pm SD & & & & & \\
\hline 1 & + & Colistin & $2250.0 \pm 137.8$ & 3420 & 1.52 & 95 & 401.8 & 6.12 \\
2 & - & - ve & $2143.5 \pm 183.7$ & 3280 & 1.53 & 100 & 400.1 & 8.57 \\
3 & + & Non-treated & $1858.7 \pm 275.6$ & 3210.5 & 1.73 & 72.5 & 222.6 & 14.83 \\
\hline
\end{tabular}

* EEF: European Efficacy Factor. **CV\%: Uniformity

Tested S. Enteritidis isolates are classified to 11 profiles. Regarding result of MDR, it was recorded that all tested isolates are resistant to two - nine antibiotics with resistant index 0.2- 0.9 (Table 4). Only two isolates are NDR (12.5\%), most of isolates 10/16 (62.5\%) are MDR and 4/16 (25\%) are EDR having resistance to 8-9 antibiotics (Table 3). Our results are similar to result of Elkenany et al. (2019) where MDR was determined in $76.7 \%$ of the isolates with resistance index of $0.2-0.6$. Isolates of resistant index higher than 0.2 are of high risk in control (Miranda et al., 2008). MDR was reported in 54.8\% of $S$. enteritidis isolates and 20\% were EDR (Aditya, 2015). Also, it was found that S. Enteritidis isolates were $63.9 \%$
(Medeiros et al., 2011) and 90\% (Rizi et al., 2015) were MDR.

Infected groups at the $2^{\text {nd }} \mathrm{dpi}$ showed clinical signs including ruffled feathers, off food, depression, closed eyes, wet dropping to diarrhea, pasty vent that lasted for the $7^{\text {th }}$ day in control non-treated group that showed marked loss of weight (Abd El-Ghany et al., 2012b). The mortality stared at the $4^{\text {rd }}$ till the $9^{\text {th }}$ dpi in non-treated. Lesion including congested liver and spleen and sever enteritis. The late mortality and sacrificed birds in nontreated birds show focal areas of necrosis on liver, spleen, intestinal mucosa and caecal cores. Clinical signs were subside in the $2^{\text {nd }}$ day from treatment with improve in feed 
intake and drooping. Sacrificed birds at 5 and 7 days from the start of treatment showed mild or non-obvious lesions.

Mortality rate are shown in (Table 5), the highest mortality rate was $27.5 \%$ in infected non-treated group 3 (Abd El-Ghany et al., 2012b) and 5\% in treated (Group 1) while control negative (Group 2) showed 0\% mortalities. Lesions in dead birds were congested muscles, hemorrhages on body and heart fat, congested internal organs and inflamed intestinal mucosa with watery to mucoid contents. The lesions were markedly severe in infected non treated broilers than treated ones. Similar lesions caused by $S$. Enteritidis in broiler chickens (Abd El-Ghany et al., 2012b).

Collected samples from dead infected birds including liver, heart, spleen and cecum were positive for reisolation of $S$. Enteritidis indicates the microorganism was the cause of mortality. Highest mortality rate in was in $S$. Enteritidis experimentally infected group3is matched with result of Abd El-Ghany et al. (2012b) and Morsy (2012) who reported that $S$. Enteirtidis is one of the bacterialcauses for high mortalities in broiler chickens. Mild signs and low mortality in treated group proved effect of colistin on $S$. Enteritidis. It was found that addition of colistin in broiler diet decrease the rate of infection of flocks and contamination of broiler carcasses due to S. Enteritidis (Fard, 2004), recently, Osman et al. (2014) noticed that $S$. enteric spp., that isolated from imparted duckling showing $100 \%$ sensitivity to colistin.

$S$. Enteritidis intestinal count in sacrificed infected non-treated (group 3) was higher $\left(3 \times 10^{6}, 2.5 \times 10^{7}\right.$ and $2.5 \times 10^{5}$ at 3,5 and 7 from medication, respectively) than in treated group $1\left(2.6 \times 10^{4}, 1.2 \times 10^{3}\right.$ and $0.5 \times 10^{3}$ at 3,5 and 7 from medication, respectively). This result proved that the used Colistin was effective in reducing clinical signs; lesion and intestinal content in $S$. Enteritidis infected treated broiler chickens (Fard, 2004). Colistin was effective against broiler infections caused by MDR $P$. aeruginosa, A. baumannii and Enterobacteriaceae (Rasool et al., 2018). Colistin sulfate have specific and selective activity against intestinal bacteria as it is not absorbed and act local in the gastrointestinal tract (Collell and Segura, 2013).

Regarding production performance (Table 6) infected non-treated group showed the lowest ABW $(1858.7 \pm 275.6 \mathrm{gm})$ at the end of the $5^{\text {th }}$ week followed by control negative group $(2143.5 \pm 183.7 \mathrm{gm})$ and the highest was in infected colistin treated which was $2250.0 \pm 137.8 \mathrm{gm}$ (Table 2). This result was matched with who noticed that chickens infected with $S$. Enteritidis organism had lower body weight compared to the controls.

FCR infected non-treated was the lowest (1.73), followed by colistin sulphate (1.52) and control negative (1.51). It is clearly noticed that treated group showed FCR close to control negative one. Liveability was 95, 100 and $72.5 \%$ in treated, non-treated and negative group; respectively (Table 6). Higher EEF in treated (402.8) followed by control group (400.1), while the nontreated infected showed the lowest factor (222.6). CV\% in treated is the highest (6.12) followed by control group (8. 57) and that of nontreated infected showed the lowest (14.83). Our results agree with those of (Bozorgmehri, 2004) where colistin in feed reduces $S$. Enteritidis in broiler farm and increases live BWG (14\%) and FCR (8\%).

Treated group showed good uniformity (CV \%) $6.12 \%$ than control negative $8.57 \%$ and infected nontreated group $14.83 \%$.

\section{Conclusions}

It could be concluded that $S$. Enteritidis is prevalent in broiler chicken flocks. Most of isolates are MDR. Experimental infection of broiler with $S$. Enteritidis resulted in high mortality and addition of colistin sulphate in drinking water controlled the infection and restores the productivity of infected broiler chickens.

\section{Acknowledgment}

Authors are thankful for Poultry disease departments in both in Faculty of Vet. Med Cairo University and National Research Centre.

\section{Author's contributions}

AMA and MMA designed and planned the study. EMH and AMG collect samples. All authors share laboratory tests, experimental work, and writing, drafted, revised the manuscript and approved the final manuscript.

\section{REFERENCES}

Abd El-Ghany AW, El-Shafii SAS, Soumaya SA, et al., 2012a. A Survey on Salmonella species isolated from chicken flocks in Egypt. Asian J Anim Vet Adv, 7: 489-501.

Abd El-Ghany AW, El-Shafii SAS, Hatem ME, et al., 2012b. A Trial to Prevent Salmonella Enteritidis Infection in Broiler Chickens Using Autogenous Bacterin Compared with Probiotic Preparation. J Agric Sci, 4: 91-108.

Abdallah M, 1995. Microbiological studies of naturally and experimentally occurring salmonella organisms in poultry and their environment inFayoum governorate. Thesis; $\mathrm{PhD}$; (Bacteriology), Cairo University, Fac Vet Med, Beni-Suef Branch.

Aditya A, 2015. Drug resistant Salmonella in broiler chicken sold at local market in Bangladesh and its public health significance. African J Biotechnol, 14: 2995-3000.

Akinyemi KO, Phillip W, Beyer W, et al., 2007. In-vitro antimicrobial susceptibility Patterns of Salmonella enterica serovars and emergence of Salmonella phage type DT071 in a suspected community-associated outbreak in Lagos, Nigeria. J Infec Develop Countr, 1: 48-54.

Altekruse S, Koehler J, Hickman-Brenner F, et al., 1993. Comparison of Salmonella Enteritidis phage types from egg-associated outbreaks and implicated laying flocks. Epidemiol Infect, 110: 17- 22.

Altekruse SF, Bauer N, Chanlongbutra A, et al., 2006. Salmonella Enteritidis in Broiler Chickens, United States, 2000-2005. Emerg Infect Dis, 12: 1848-1852.

Asif M, Rahman H, Qasima M, et al., 2017. Molecular detection and antimicrobial resistance profile of zoonotic Salmonella enteritidis isolated from broiler chickens in Kohat, Pakistan. J Chinese Medical Ass, 80: 303-306.

Baggesen DC, Olsen JE and Bisgaard M, 1992. Plasmid profiles and phage types of Salmonella typhimurium isolated from successive flocks of chickens on three parent farms. Avian Pathol, 21: 569-579.

Bale J, Bennett PM, Beringer JE, et al., 1993. The survival of bacteria exposed to desiccation on surfaces associated with farm buildings. J Appl Bacteriol, 75: 519-528. 
Barrow PA, 1991. Experimental infection of chickens with Salmonella Enteritidis. Avian Pathol, 20: 145-153.

Bozorgmehri FMH, 2004. The effect Colistin sulfate in feed on controlling of Salmonella enteritidis contamination in broiler farm. Arch Razilins, 58: 105-110.

Carli KT, Unal CB, Caner V, et al., 2001. Detection of Salmonella in chicken feces by a combination of tetrathionate broth enrichment, capillary PCR, and capillary gel electrophoresis. J Clin Microbiol, 39: 1871-1876.

Christopher AF, Hora S and Ali Z, 2013. Investigation of plasmid profile, antibiotic susceptibility pattern multiple antibiotic resistance index calculation of Escherichia coli isolates obtained from different human clinical specimens at tertiary care hospital in Bareilly-India. Ann Trop Med PH 6: 285-289.

CLSI, 2013. Clinical and Laboratory Standards Institute, Performance Standards for Antimicrobial Susceptibility Testing. Susceptibility Testing. $26^{\text {th }}$ ed. CLSI supplement M100S. Clinical and Laboratory Standards Institute, 950 West Valley Road, Suite 2500.

da Costa PM, Loureiro L and Matos AJF, 2013. Transfer of multidrug-resistant bacteria between intermingled ecological niches: The Interface between Humans, Animals and the Environment. Int J Environ Res Public Health, 10: 278-294.

Elkenany R, Elsayed MM, Zakaria IA, et al., 2019. Antimicrobial resistance profiles and virulence genotyping of Salmonella enterica serovars recovered from broiler chickens and chicken carcasses in Egypt. BMC Vet Res, 15: 124.

El-Sharkawy H, Tahoun A, El-Gohary AEA, et al., 2017. Epidemiological, molecular characterization and antibiotic resistance of Salmonella enterica serovars isolated from chicken farms in Egypt. Gut Pathog, 10: 9:8.

Fard MH, 2004. The Effect of Colistin Sulfate in Feed on the Controlling of Salmonella Enteritidis Contamination in a Broiler Farm. Arch Razi Ins 58: 105-110.

Fasure AK, Deji-Agboola AM and Akinyemi KO, 2012. Antimicrobial resistance patterns and emerging fluoroquinolone resistant Salmonella isolates from poultry and asymptomatic poultry workers. African J Microbiol Res, 6: 2610-2615.

Forbes BA, Sahm DF and Weissfeld AS, 2002. Diagnostic microbiology. $11^{\text {th }} \mathrm{Ed}$. Mosby, Inc. USA.

Gong J, Zhang J, Xu M, et al., 2014. Prevalence and fimbrial genotype distribution of poultry Salmonella isolates in China (2006 to 2012). Appl Environ Microbiol, 80: 687-93.

Greenwood D, Slack RC and Peutherer JF, 2005. Medical microbiology.A Guide to Microbial Infections: Pathogensis, Immunity, Laboratory Diagnosis and Control, $16^{\text {th }}$ Ed. Churchill Livingstone China.

Hafez MH, 2001. Salmonella infections in poultry: Diagnosis and control. Periodicum Biologorum 103: 103-113.

Jorgensen JH and Ferraro MJ, 2009. Antimicrobial susceptibility testing: a review of general principles and contemporary practices. Clin Infect Dis, 49: 1749-1755.

Kauffmann F, 2001. The Bacteriology of Enterobacteriaceae. The Williams \& Wilkins Co., Baltimore.

Marin C, Balasch S, Vega S, et al., 2011. Sources of Salmonella contamination during broiler production in Eastern Spain. Prev Vet Med, 98: 39- 45.

Medeiros MA, Oliveira DC, Rodrigues DP, et al., 2011. Prevalence and antimicrobial resistance of Salmonella in chicken carcasses at retail in 15 Brazilian cities. Rev Panam Salud Publica, 30: 555-560.

Menghistu HT, Rathore R, Dhama K et al., 2011. Isolation, Identification and Polymerase Chain Reaction (PCR) Detection of Salmonella Species from Field Materials of Poultry Origin. Int J Microbiol Res, 2: 135-142.

Mezal EH, Sabol A, Khan MA, et al., 2014. Isolation and molecular characterization of Salmonella enterica serovar
Enteritidis from poultry house and clinical samples during 2010. Food Microbiol, 38: 67-74.

Miranda JM, Vázquez BI, Fente CA, et al., 2008. Comparison of antimicrobial resistance in Escherichia coli, Staphylococcus aureus, and Listeria monocytogenes strains isolated from organic and conventional poultry meat. J Food Prot, 71: $2537-2542$.

Mohamed AE, 1998. Occurrence of food poisoning organisms in poultry products with special reference to Campylobacter. PhD. thesis (Meat Hygiene), Fac Vet Med, Zagazig University.

Morsy EA, 2012. Studies on bacterial infections causing high mortality in broiler chicks.MD. Thesis, Poultry and Rabbit Diseases, Cairo University.

O'Brien JDP, 1988. Salmonella Enteritidis infection in broiler chickens. Vet Rec, 8: 214-218.

Okamoto AS, AndreattiFilho Rl, Lima ET, et al., 2007. Immunological evaluation of the intestinal mucosa of broiler chicks treated with lactobacillus spp. and challenged with Salmonella Enteritidis. Braz J Poult Sci, 9: 259- 262.

Osman KM, Marouf SH, Zolnikov TR et al., 2014. Isolation and characterization of Salmonella enterica in day-old ducklings in Egypt. Pathog Glob Health, 108: 37-48.

Paul S, Bezbaruah RL, Roy MK, et al., 1997. Multiple antibiotic resistance (MAR) index and its reversion in Pseudomonas aeruginosa. Letters Appl Microbiol, 24: 169-171.

Putturu R, Lakkineni M and Rao LV, 2012. Study on the incidence of Salmonella Enteritidis in Poultry and meat Samples by Cultural and PCR Methods. Vet World, 5: 541545.

Quinn PJ, Carter ME, Markey BK, et al., 2002. Veterinary Microbiology and Microbial diseases, Great Briian by MPG, Book. $1^{\text {st }}$ Ed., Bodmin, Cornwall, UK.

Rabie SN, Khalifa ON, Radwan EIM, et al., 2012. Epidemiological and Molecular Studies of Salmonella Isolates from Chicken, Chicken Meat and Human in Toukh, Egypt. Global Vet 8: 128-132.

Rasool S, Ali Q and Rasool T, 2018. Application of Colistin to Combat Bacterial Diseases in Broiler Chickens. Int J Nanotechnol Allied Sci, 2: 3- 6.

Reynolds, DJ, Davies RH, Richards M, et al., 1997. Evaluation of combined antibiotic and competitive exclusion treatment in broiler breeder flocks infected with Salmonella enterica serovar Enteritidis. Avian Pathol, 26: 83-95.

Rizi SK, Peerayeh NS, Bakhshi B, et al., 2015. Prevalence of ESBLs and integrons in clinical isolates of Salmonella spp. from four hospitals of Tehran. Int $\mathrm{J}$ Enteric Pathog, 3 : e21820.

Sainsbury D, 1984. System of management in: Poultry health and management. $2^{\text {nd }}$ ED. Granda Publishing [TD], 8 Grafton St., London.WIX3LA.

Seuna E, Schneitz C, Nurmi E, et al., 1980. Combined therapy of Salmonella infection in chickens by antimicrobial agents followed by cultured cecal bacteria. Poult Sci, 59: 1187-1192.

Shittu A, Raji AA, Madugu SA, et al., 2014. Predictors of death and production performance of layer chickens in opened and sealed pens in a tropical savannah environment. BMC Vet Res, 10: 214

Sneath PHA, Mair NS, Sharpe ME, et al., 1986. Bergey's Manual of Systematic Bacteriol. Vol. 2. Williams and Wilkins Co. Baltimore.

Soliman S, Seida AA, Zou El-Fakar SA, et al., 2018. Salmonella infection in Broiler flocks in Egypt. Bioscience Res. 15: 1925-1930.

Suzuki S., 1994. Pathogenicity of Salmonella Enteritidis in poultry. Int J Food Microbiol, 21: 89-105.

Timms, LM, Marshall RN and Breslin MF, 1990. Laboratory assessment of protection given by an experimental S. Enteritidis PT4 inactivated adjuvant vaccine. Vet Rec, 127: 611-614. 